OPEN ACCESS

Edited by:

Kate Huihsuan Chen,

National Taiwan Normal University,

Taiwan

Reviewed by:

Robert E. Anthony,

United States Geological Survey

(USGS), United States

Masaki Kanao,

National Institute of Polar Research,

Japan

*Correspondence:

Zeinab Jeddi

zeinab.jeddi@uib.no;

zeinab.jeddi@gmail.com

Specialty section:

This article was submitted to

Solid Earth Geophysics,

a section of the journal

Frontiers in Earth Science

Received: 31 January 2020

Accepted: 15 April 2020

Published: 13 May 2020

Citation:

Jeddi Z, Voss PH, Sørensen MB,

Danielsen F, Dahl-Jensen T, Larsen TB, Nielsen G, Hansen A, Jakobsen $P$ and Frederiksen $P O$

(2020) Citizen Seismology

in the Arctic. Front. Earth Sci. 8:139.

doi: 10.3389/feart.2020.00139

\section{Citizen Seismology in the Arctic}

\author{
Zeinab Jeddi ${ }^{*}$, Peter H. Voss ${ }^{2}$, Mathilde B. Sørensen ${ }^{1}$, Finn Danielsen ${ }^{3}$, \\ Trine Dahl-Jensen², Tine B. Larsen², Gerth Nielsen"4, Adam Hansen, Pâviârak Jakobsen ${ }^{6}$ \\ and Per Ole Frederiksen ${ }^{7}$
}

\begin{abstract}
' Department of Earth Science, University of Bergen, Bergen, Norway, ${ }^{2}$ Geological Survey of Denmark and Greenland, Copenhagen, Denmark, ${ }^{3}$ Nordic Foundation for Development and Ecology, Copenhagen, Denmark, ${ }^{4}$ Independent Researcher, Akunnaaq, Greenland, ${ }^{5}$ Independent Researcher, Aasiaat, Greenland, ${ }^{6}$ Qeqertalik Municipality, Aasiaat, Greenland, ${ }^{7}$ Independent Researcher, Attu, Greenland
\end{abstract}

Landslides, earthquakes and other natural disasters are expected to increase in the Arctic, yet our ability to make informed decisions about safety is tightly limited by lack of data. As part of the Integrated Arctic Observation System (INTAROS) project, geophones were installed by residents in Greenland and by University of Bergen in Svalbard in 2018. The purpose of the installations was to explore challenges and benefits of community-based data collection for seismological monitoring in the Arctic region. Raspberry Shake units with one/three-component velocity sensors were selected for the deployment, due to their user-friendly configuration, easy installation, and well established digital platform and web services. The purpose of engaging community members in the use of geophone sensors was to monitor earthquakes, cryoseisms (events generated by ice mass), and landslides. We report our findings with respect to challenges regarding the installation and operation of the Raspberry Shake sensors at both locations. Connecting community-based recordings with permanent seismological networks improved both the detection capability and the data support for understanding seismic events in Greenland. In contrast, finding suitable locations for deployments in Longyearbyen turned out to be challenging, because most buildings are constructed on poles due to the permafrost and indoor space is expensive. Promoting citizen seismology in the Arctic could improve monitoring of seismic events in the Arctic while simultaneously raising community awareness of natural hazards.

\section{Keywords: citizen seismology, Raspberry Shake, Arctic, seismology, citizen science, Greenland, Longyearbyen, Svalbard}

\section{NOMENCLATURE}

\section{CS: citizen seismology}

INTAROS: Integrated Arctic Observation System

UNIS: University Center in Svalbard.

\section{INTRODUCTION}

Natural disasters, e.g., landslides or earthquakes among others, are likely to increase with the changes in the climatic conditions in the Arctic (e.g., Dahl-Jensen et al., 2004; Hestnes et al., 2016; Clinton et al., 2017). The European Union funded project, Integrated Arctic Observation System (INTAROS) ${ }^{1}$, aims to contribute to innovative solutions to fill some of the critical gaps

\footnotetext{
${ }^{1}$ see http://intaros.eu/
} 
in the in situ observation networks in the Arctic. Most efforts to monitor natural phenomena in the Arctic have been conducted by scientists and are usually "externally driven" approaches in which experts from outside the study area organize the experiment and process the data (Danielsen et al., 2009, 2020). Involvement of community members in one or more steps of the monitoring process is a complementary way to improve the knowledge of the natural phenomena and is included as one of the main components of the INTAROS ${ }^{2}$. Some scientists question the quality of data due to the limited facilities and methods that can be used by non-experts while installing instruments and collecting data (Root and Alpert, 1994; Penrose and Call, 1995). However, community-based approaches are rapidly increasing among different scientific branches and expected to result in dynamic interaction between locals, authorities and scientists (Johnson et al., 2015; Hecker et al., 2018; Cuyler et al., 2020; Eicken et al., under review). The "MyShake" and "QuakeCatcher" platforms are examples of citizen science approaches in seismology. "MyShake" connects users from all over the world to form a global mobile-phonebased earthquake early warning network (Allen et al., 2020). "QuakeCatcher" is a research project aiming to provide critical earthquake information using computer-based accelerometers (Cochran et al., 2009).

Here, we will focus on seismological data collection in two villages in western Greenland (Figures 1A,B) and in Longyearbyen, Svalbard (Figures 1A,C). The permanent seismological network is not dense in the Arctic due to (1) difficult access to the area and (2) the earthquakes impose less risk to the region compared to other regions due to sparse human populations. In addition to the recent technologies, which have improved the access to the region, continued climatic changes may provide easier access to the Arctic in the future. However, limited infrastructure (e.g., power and communication systems) and strict environmental regulations continue to keep the in situ research efforts expensive and logistically challenging in the Arctic. The Geological Survey of Denmark and Greenland and University of Bergen have worked with local citizens in monitoring the seismic activity in Greenland and Svalbard to address the challenges and benefits of citizen seismology (CS) data. By engaging locals in this pilot study, we would like to point to advantages and challenges in the interaction between society and scientists in different social environments (Greenland and Svalbard in this case). We also show the achieved monitoring improvements by using denser seismic networks.

\section{THE GEOPHONE SYSTEM: RASPBERRY SHAKE}

We chose the Raspberry Shake ${ }^{3}$ instrument for citizen seismological monitoring in this study (Raspberry Shake, 2016). The Raspberry Shake seismograph is an all-in-one, Internet-Of-Things (IoT) plug-and-go solution for seismological

${ }^{2}$ see https://mkp28.wixsite.com/CBM-best-practice

${ }^{3}$ see https://raspberryshake.org/ applications, which can detect and record high-frequency $(0.5-15 \mathrm{~Hz})$ energy from earthquakes. It was developed by OSOP (Observatorio Sismológico del Occidente de Panamá), S.A., a geophysical instrument company headquartered in Panamá, and integrates geophone sensors, digitizers, period-extension circuits and a computer into a single enclosure. The units used in Greenland are both equipped with vertical geophones, in Longyearbyen one uses a vertical geophone and one with three orthogonal geophones. All units use the Network Timing Protocol (NTP) for timing as opposed to the satellite-derived timing commonly used for most seismic stations. Performance of Raspberry Shakes has been evaluated in several studies with the conclusion that they are suitable to complement existing networks for studying local and regional earthquakes (e.g., Anthony et al., 2018; Manconi et al., 2018; Hicks et al., 2019). The instruments are also becoming increasingly popular as an educational tool for teaching and public science exhibitions (e.g., BLOSSM, Bridging Local Outreach \& Seismic Signal Monitoring, project in Oklahoma ${ }^{4}$ ). The Raspberry Shake is low cost, easy to install/maintain, and has near real-time data transmission. Power and an internet connection are the only technical requirements which make the Raspberry Shake suitable for engaging community members. Note that even if there is no internet, the instrument has internal data storage. An additional requirement is to install the instrument at a quiet location with little man-made and natural noise. The installation needs to have good coupling to the ground, preferably to bedrock. Information on online Raspberry Shake sensors is accessible for display through a website ${ }^{5}$ where data can also be displayed.

\section{GREENLAND CASE}

In Greenland, close collaboration exist between fishermen, hunters, and the authorities (Piniakkanik Sumiiffinni Nalunaarsuineq, PISUNA ${ }^{6}$ ), where community members (e.g., an experienced fisherman) keep track of changes in the status of living resources, discuss and interpret their observations, and propose management interventions to the authorities (Danielsen et al., 2014). The Greenlandic Ministry of Fisheries, Hunting, and Agriculture in collaboration with Qeqertalik and Avannaata municipalities has developed this monitoring and management system specifically to enable fishermen and hunters to document trends in living resources, to propose management decisions themselves and to take an active role in stewardship of the resources. In April 2018, two families living in the villages Akunnaaq (Figures 1D,E) and Aasiaat in Disko Bay area ("DB" in Figure 1B) in western Greenland, and already engaged in PISUNA, installed Raspberry Shakes in their basements. These CS monitoring stations have been named AKUG and ASIG, respectively (Figure 1B). The installation instruction was simply to place the instrument on bedrock, connect the instrument to their Internet router via the LAN cable and power up the unit.

\footnotetext{
${ }^{4}$ see http://www.ou.edu/ogs/education/Educopps

${ }^{5}$ see https://raspberryshake.net/stationview/

${ }^{6}$ see http://www.pisuna.org/and https://eloka-arctic.org/pisuna-net/en/
} 

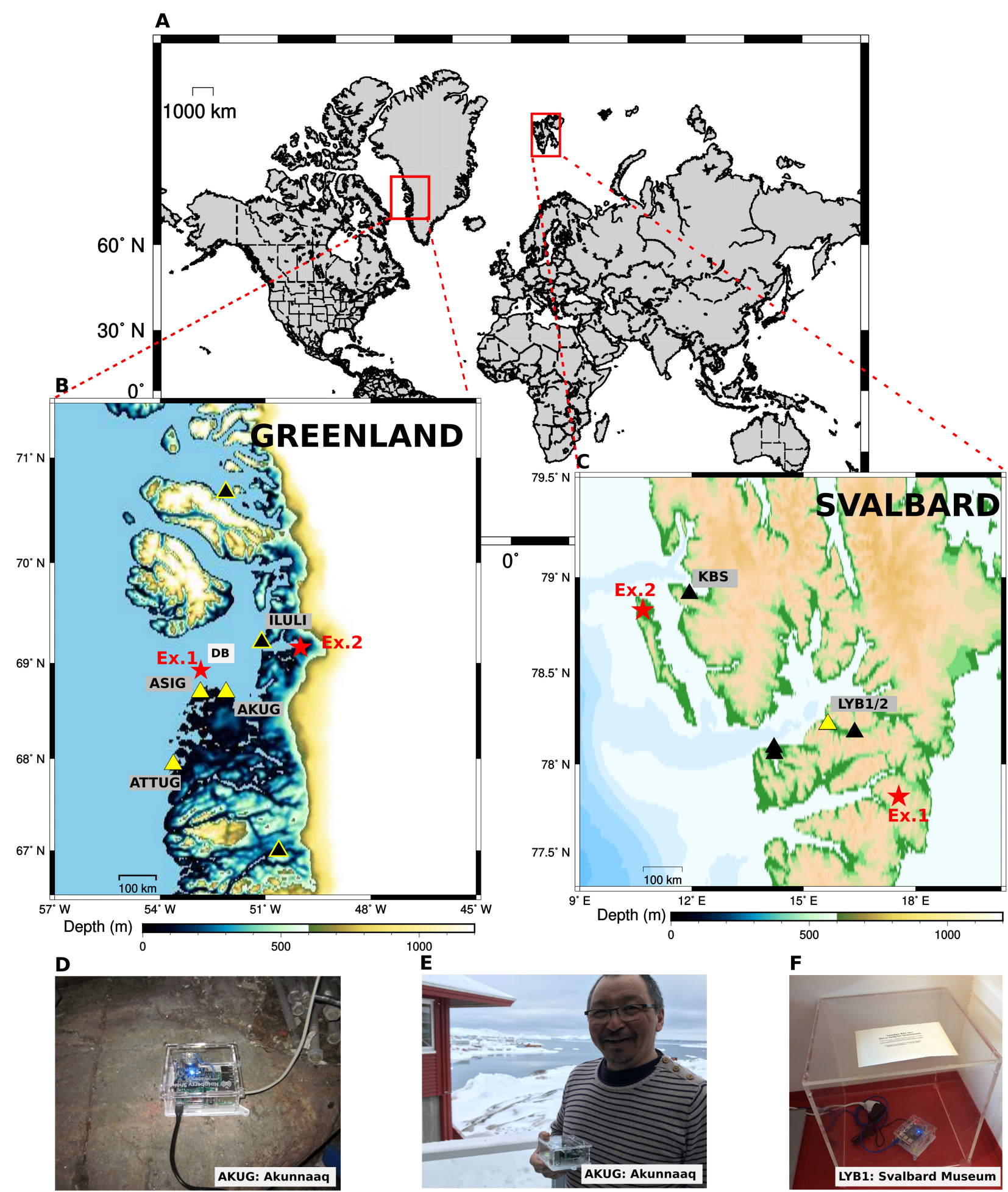

FIGURE 1 | (A) World map. The two study areas are shown with red boxes. (B) Map of west Greenland. Citizen seismology (CS) sensors and permanent stations are shown with yellow and black triangles, respectively. "DB" refers to "Disko Bay." "Ex.1" and "Ex.2" are the location of two events in Figures 3B,C. (C) Map of Svalbard. CS sensors and permanent stations are shown with yellow and black triangles, respectively. "Ex.1" and "Ex.2" are the location of two events in Figures 4D-I. (D) Sensor installed in Akunnaaq, Greenland (Photo: G. Nielsen). (E) Gerth Nielsen*, Akunnaaq, before installing CS sensor on the rock below his house (Photo: F. Danielsen). (F) Sensor installed in Longyearbyen, Svalbard museum. The Raspberry Shake is covered with a glass lid. Bathymetry in panels (B) and (C): ETOPO1 taken from National Oceanic and Atmospheric Administration (NOAA; Amante and Eakins, 2009). (*Written informed consent was obtained from the individual in Figure $\mathbf{1 E}$ for the publication in this article). 
The units automatically connected to the Raspberry Shake server and started uploading data. The ASIG sensor moved to a new location in Attu in 2019 due to the landowner not being able to host the instrument any longer. The new site is named ATTUG. Therefore, AKUG was recording between April 2018 and July 2019, ASIG recorded data between April 2018 and December 2018 and then ATTUG was monitoring between June 2019 and December 2019.

Since the first data became available on the Raspberry Shake server, the data has been analyzed together with data from the permanent seismological stations in Greenland. The performance of the deployments was first assessed by computing daily power spectral densities for the entire deployment period. The power spectral density of seismic recording is defined as the power of the signal distributed over a range of frequencies and it is the primary method by which all seismometers are evaluated in terms of noise. We calculated the power spectral densities over hourly segments with $50 \%$ overlap and then stacked them to daily spectrograms. The processing is done using methodology of McNamara and Buland (2004) implemented in the open-source software Seisan (Havskov et al., 2020). The data were plotted as probability density functions for the vertical component of the deployments in Greenland (Figures 2A-C). The poor performance of the Raspberry Shake at long periods ( $>10 \mathrm{~s})$ is expected due to high levels of instrument self-noise (Anthony et al., 2018). Thus, these stations are not observing ambient ground motion at longer periods and only one of the microseismic peaks, the secondary microseismic peak, is visible. The noise levels at higher frequencies are lower than the New High Noise Model of Peterson (1993); however, they are partly limited by the instruments' self-noise. At stations AKUG and ASIG, the spectrograms are able to monitor actual ground motion between 0.5 and $5 \mathrm{~s}$. In comparison to the other two stations, the spectrograms at ATUUG have higher ambient noise level at wider range between 0.1 and $5 \mathrm{~s}$. A narrow band around $10 \mathrm{~Hz}$ with slightly higher noise level in ATUUG may be due to the day time activities near the sensor. A similar quality assessment is performed for one of the nearby permanent broadband stations (ILULI) for comparison (Figure 2D).

The two CS sensors provided very useful data and their signal to noise ratio for many events was comparable to permanents stations at frequencies above $4.5 \mathrm{~Hz}$ (Figures 3B,C). To detect new events, the daily screening for seismic events in Greenland is done manually on selected stations. Data from observed events are thereafter extracted in 10 min segments from all stations including the CS sensors and analyzed. For some events the CS sensors were closer to the epicenter than any of the permanent stations (Figure 3B) and for some events a location of the event would not have been possible without the CS sensors. During the time period between April 20, 2018 and September 23, 2019, 280 events have been recorded by the CS sensors (Figure 3A). Thirteen of those events were observed on only one or two seismic sensors and 48 events were observed on less than four seismic sensors. The CS sensors thereby contributed to an acceptable location of 232 events. By relocating the 280 events without the observations from the CS sensor we find that 71 events are observed by less than four seismic stations. The CS sensors have enabled the location, by four or more stations, of
23 events and have improved the location of 209 events. The continuous screening, phase readings and location processes are done in Seisan software (Havskov et al., 2020).

The Disko Bay ("DB" in Figure 1B) area is subject to high glacial activity from the nearby outlet glaciers. During calving (breaking of ice from the glacier edge) or other movement of the cryosphere, seismic signals detectable at long distances may be generated (Podolskiy and Walter, 2016). Of the 280 events observed on the CS sensors, 53 have been classified as of cryospheric origin (blue stars in Figure 3A), mainly from glacial activity during calving or from other displacements of glaciers or icequakes. The classification is done manually during analyses based on frequency content of seismic events, epicenter location and analyst experience. The cryo-generated seismic signals have different signatures. Some are several minutes in duration without clear P-phases and with multiple S-phases and peak amplitudes between 5 and $10 \mathrm{~Hz}$, larger events often generate low frequency signals (below $0.03 \mathrm{~Hz}$ ) with amplitudes equal to magnitude five earthquakes (Nettles and Ekström, 2010). Smaller events are similar in duration to smaller earthquakes with magnitudes of 2 or lower, but typically with lower frequencies. It is not unusual to see two or three cryoseismic events within a 15 min window. The remaining events have been presumed to be of tectonic origin (red stars in Figure 3A). Figure 3 shows event locations in western Greenland which are processed using CS sensors together with one example for each event type. In the first example (Figure 3B), the seismic recording is classified as a tectonic event and the two CS units are nearest to the epicenter. In this case, the two Raspberry Shakes have higher signal-to-noise ratios than the permanent station for the $\mathrm{P}$-wave phases and they improve the event location. Figure $\mathbf{3 C}$ is an example of a cryoseismic event that was also well recorded on the Raspberry Shakes.

\section{LONGYEARBYEN (SVALBARD) CASE}

The deployment of two CS sensors in Svalbard was carried out in July 2018. To accommodate the technical requirements for deployment (access to power and internet), as well as the citizen science perspective of the study, we wished to locate deployments within the town of Longyearbyen. To keep up the educational value of having these instruments in town, several public places were approached (e.g., the library, school, church, Svalbard museum, Radisson Blu Polar hotel, Svalbard art gallery, the Fire station, and airport). However, unexpectedly, only two places could fulfill our basic technical requirements (power and a cabled internet connection), provide appropriate locations for the sensors (on the ground floor of the building) and were willing to host the instruments: Svalbard museum and Radisson Blu Polar hotel. Most potential sites were abandoned due to lack of power and/or Internet connection at the location that could be provided by the host. Also, due to the high cost and limited availability of indoor area in Longyearbyen, our request was rejected by some hosts due to lack of space, despite the fact that these instruments do not need much space (Figure 1F). A major challenge turned out to be that nearly all buildings in Longyearbyen (and Svalbard) are built on poles (timber poles hammered into the permafrost 
A

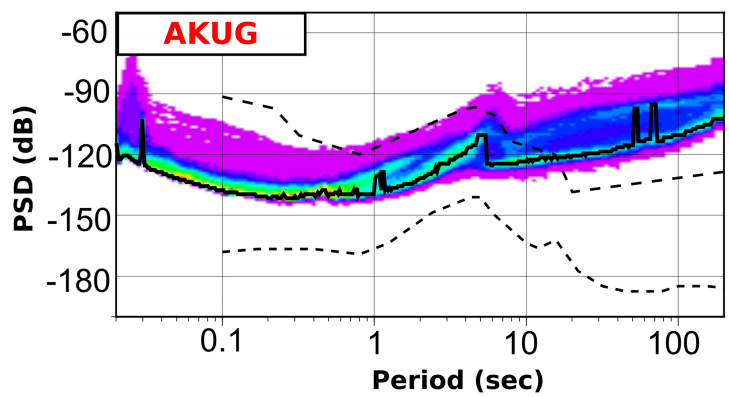

C

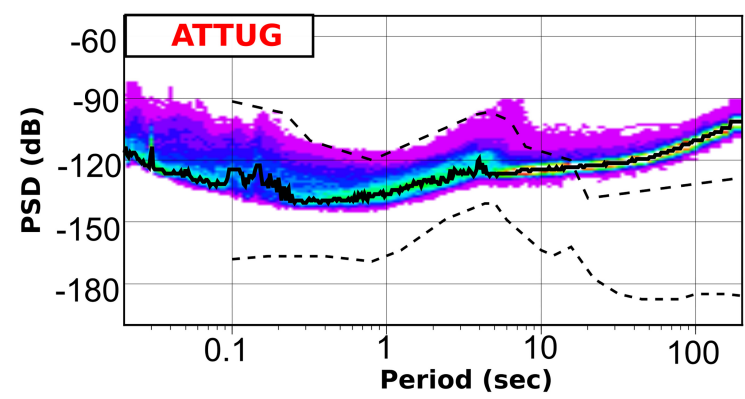

B

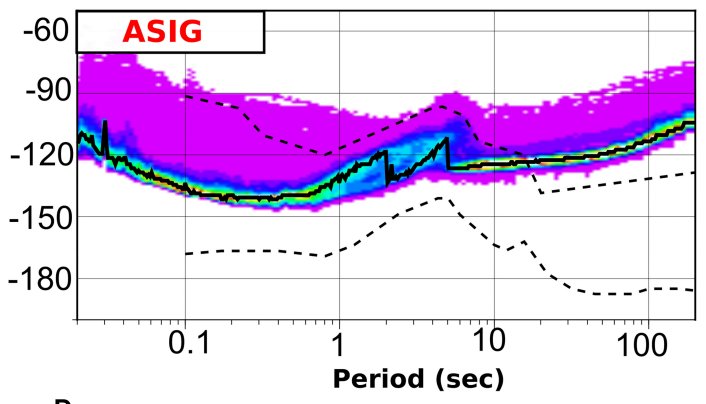

D

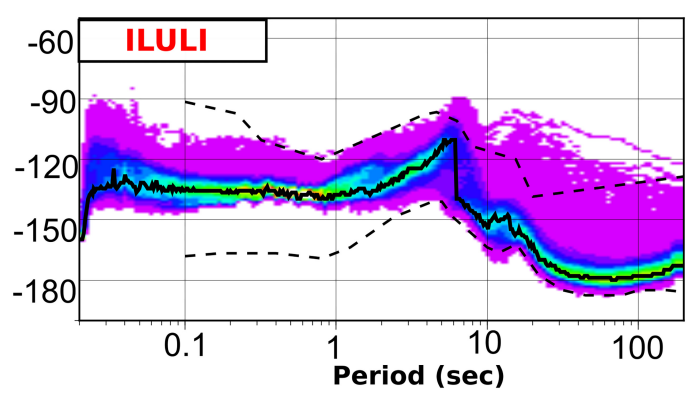

FIGURE 2 | (A-D) Hourly probability density functions of the vertical component for AKUG, ASIG, ATTUG, and ILULI installations, respectively. The dashed black lines show the global New High and Low Noise Models for seismic monitoring stations of Peterson (1993), respectively. The solid black curve is the mode value of the spectrograms. The $\mathrm{x}$-axis is logarithmic.

ground), in order to provide a stable foundation for the building in the permafrost. Such locations provide a poor coupling to the ground and will thus limit the performance of the deployments ${ }^{7}$. Both Svalbard museum and Radisson Blu Polar hotel, which were our only options in Longyearbyen, are built on poles.

The installations (Figure 1C) were both made in July 2018, in close collaboration with our hosts. In Svalbard museum, a corner of an abandoned office was used to set up the instrument and launch the recording. The host also provided a lid to protect the instrument (Figure 1F). The other instrument was installed in a storage room in Radisson Blu Polar hotel. We had access to data in nearly real time and immediately noticed the high level of noise in both locations, as expected. However, further effort to find alternative locations were not successful. The monitoring was therefore continued at the initial locations.

The performance of the data was assessed similarly for the Longyearbyen installations (Figures 4 A,B) by noise analyses through calculations of power spectral densities. However, in this case the high frequencies are also suffering from very high levels of noise, exceeding the New High Noise Model of Peterson (1993) in LYB2 (Radisson Blu Polar Hotel). The Svalbard museum installation (LYB1) is slightly better and this is probably because of the lid which is used to cover the instrument in addition to the building itself. The high noise levels confirm that the buildings in Longyearbyen, which are built on poles in the permafrost, are inappropriate for seismic monitoring. A similar

${ }^{7}$ see https://manual.raspberryshake.org/quickstart.html\#note-for-the-raspberryshake-rs3d-and-rs4d noise analysis for one of the nearby permanent stations (KBS) is shown in Figure 4C. This station has drastically lower noise levels than the CS sensors.

Initially, it was planned to have a live view of the recordings in the museum and in the hotel, to share the data with the public (mainly students and tourists). However, the high noise levels meant that few events were visible in the collected data, and it was decided to abandon the idea of public displays. Figures 4D-I show recordings from two examples with local magnitude of 1.5 and 3.6 on the CS sensors as well as on the closest permanent station (KBS).

\section{DISCUSSION AND LEARNED LESSONS}

Monitoring of seismic activity in western Greenland has been ongoing for more than 100 years (Gregersen, 1982), not due to local earthquakes, but because of Greenland's unique location for observing earthquakes on a global scale due to low level of man-made noise. However, this is to our knowledge the first time in Greenland that geophones have been established in communities and setup by local residents. In recent years, earthquake monitoring in Greenland has shown its value both for the understanding of the geological structures (e.g., Darbyshire et al., 2017) and detection of new events such as felt earthquakes, landslides (e.g., Clinton et al., 2017) and cryoseismic phenomena (e.g., Clinton et al., 2014). The cryo-generated events (e.g., Nettles and Ekström, 2010) have raised awareness globally 

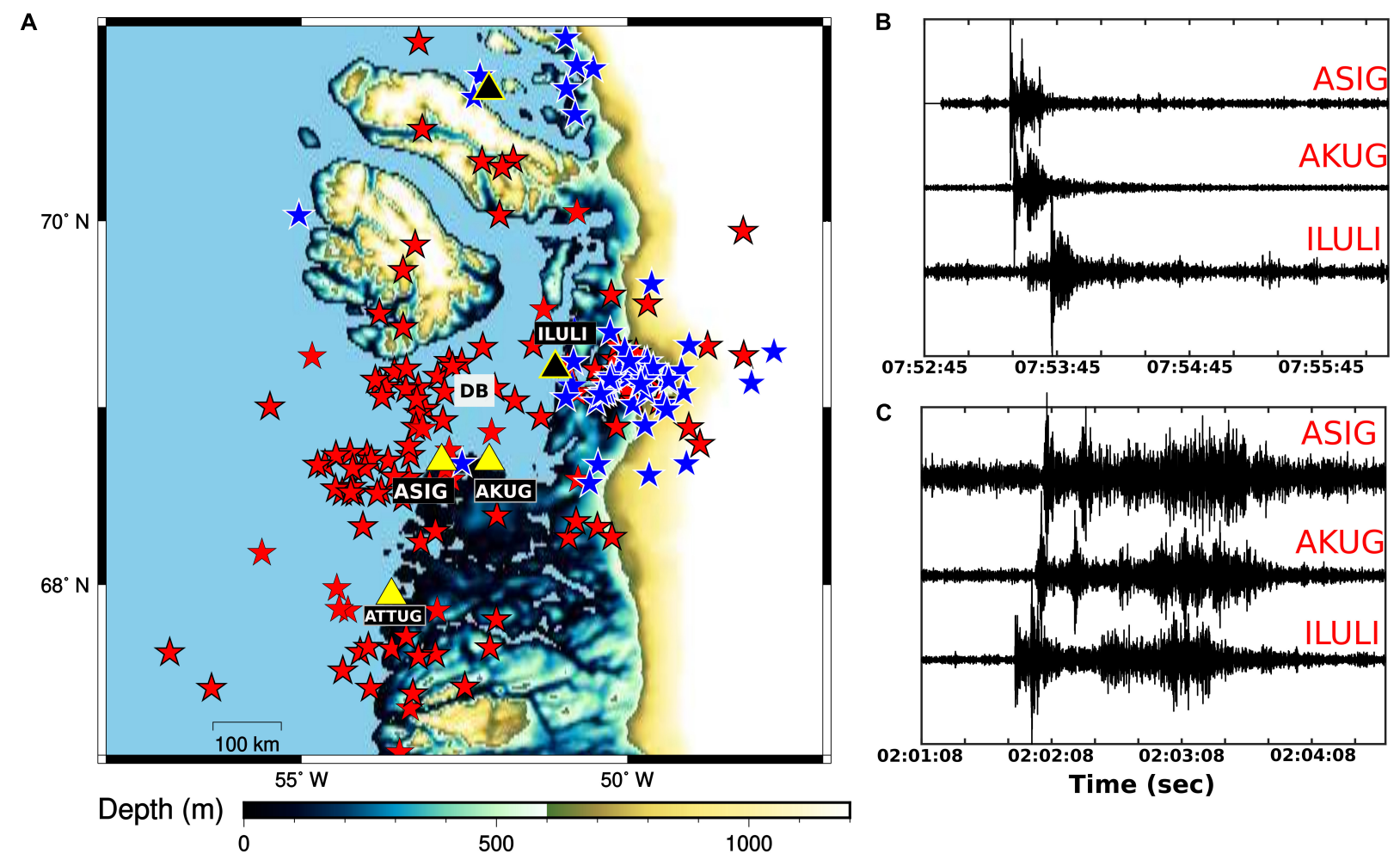

FIGURE 3 | (A) Map of west Greenland. Blue stars indicate events thought to be generated by glacial activity and red ones are classified as tectonic events. The CS sensors are the yellow triangles and permanent stations are black triangles. Three CS sensors and the closest permanent station to those deployments are marked with a label. "DB" refers to "Disko Bay." Bathymetry: ETOPO1 taken from National Oceanic and Atmospheric Administration (NOAA; Amante and Eakins, 2009). (B) Example of tectonic-originated seismic recording on May 4, 2018, 5-10 Hz bandpass. Location of the event is shown on Figure 1B as "Ex.1" (latitude: 68.93N, longitude: 52.84W). (C) Example of cryo-originated seismic recording on May 21, 2018, 5-10 Hz bandpass. Location of the event is shown on Figure 1B as "Ex. 2" (latitude: $69.15 \mathrm{~N}$, longitude: 50.00W).

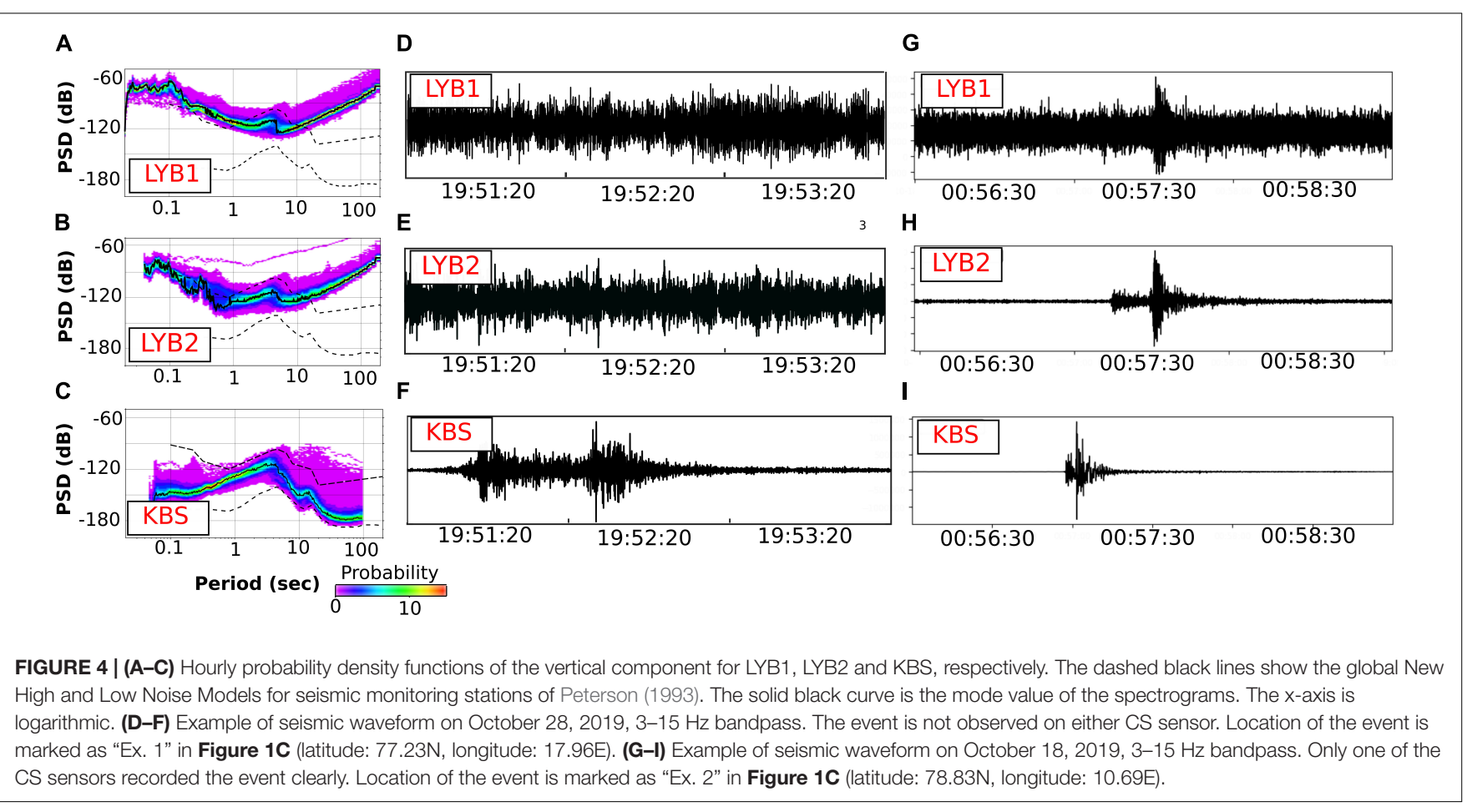


due to its possible connection to climatic changes. Recent felt earthquakes and especially the 2017 landslide north of the Disko Bay (Clinton et al., 2017) have highlighted the importance of local seismic monitoring in western Greenland.

The CS sensors provided valuable improvements in the location of seismic events in western Greenland, and in some cases unique recordings of first motion polarities of seismic waves, which are critical for understanding the causal mechanisms behind events. Furthermore, the CS sensors gave us information about the seismic noise level at the three sites (Figure 2). The noise analyses show that the site noise is below the self-noise of the Raspberry Shake and hence, future deployment of broadband seismic sensors may be selected based on these noise analyses.

The community-based data collection in western Greenland only encounters a few challenges. One seismic sensor was moved to a new settlement, so we requested the Raspberry Shake community to change the meta data for the location of the instrument on the web site, but that was unfortunately not possible at present. The Raspberry Shake stopped transmitting data from time to time, which required manual power cycling. An estimate of Internet usage by the Raspberry Shakes was not easy to attain. In Greenland, Internet is often paid by usage, and the flat rate has just recently been introduced. The data rate is therefore important for the host of a CS system, since it will affect the cost of an Internet connection.

For the Longyearbyen deployments, we faced extraordinary challenges in finding sites capable of producing useful seismic data. Longyearbyen has developed due to the coal excavation in the surrounding mountains, and has been built by the mining industry over the past century up to 1990. The town has now evolved into a varied business community with tourism, research and education being its main industries (Misund, 2017). Due to the fragile, Arctic surroundings, strict zoning and planning regulations have been implemented in Longyearbyen, and very limited space is available for construction. Due to the permafrost, most buildings are constructed on poles and thus unsuitable sites for seismological monitoring. The University Center in Svalbard (UNIS) is one of the main institutions in Longyearbyen. A large proportion of the population is affiliated with UNIS, either as employees or students, and a wide range of Arctic research is conducted there. These points introduce Longyearbyen as a special place where many people are already engaged in research in some way, and may therefore be more reluctant to participate in citizen seismological studies. In addition, indoor space is limited and expensive, and therefore finding a quiet $0.5 \mathrm{~m}$ by $0.5 \mathrm{~m}$ corner is challenging. If one wishes to further explore the potential for community-based seismological monitoring in Svalbard, one option could be to search for potential sites outside Longyearbyen. Abandoned coal mines and settlements (such as Pyramiden) would in that case be possible locations where one may find the technical facilities needed. Since some of these locations are now popular tourist destinations, the community focus could be maintained with such locations.

Our experience with deploying four CS sensors in Longyearbyen and in western Greenland suggests that local factors drive the level of success in CS in the Arctic region.
In Greenland stable locations providing high signal-to-noise ratios were obtained at each site. The families in Greenland were keen on installing the sensors at the bedrocks under their houses, probably because of the trust and respect and collaboration that already existed between the fishermen, hunters, and the authorities within the PISUNA monitoring and management system (Danielsen et al., 2017). The CS conducted in western Greenland therefore provided high quality data for the observation of seismic events in the region. In Longyearbyen, on the contrary, with the limited availability of appropriate locations (building not on poles), combined with the high cost of indoor space, finding suitable locations for the instruments turned out to be impossible. This was probably strengthened by the strong presence of research environments in Longyearbyen, making people less likely to engage themselves in "yet another research project."

Citizen seismology has high potential for raising community awareness of natural hazards. Our future efforts in Disko Bay area will therefore include meetings and workshops with the communities in Akunnaaq, Attu and Aasiaat, the municipality and central authorities. Our findings in the current study, the implications of the seismological monitoring and decision making procedures for safety in the region are going to be discussed.

\section{DATA AVAILABILITY STATEMENT}

The datasets analyzed for this study can be found in the FDSN web services (doi: 10.7914/SN/AM) with the network code "AM." "R2310," "Rf95F” are Greenland's Raspberry Shake sensor codes. "RC131" and "RD8D1" are Longyearbyen's Raspberry Shake sensor codes. The data for "KBS" station is available with the network code " $1 U$ " and location code " 10 " via the European Integrated Data Archive (EIDA) services (doi: 10.7914/SN/IU). The Swiss Seismological Service (SED) can be used to retrieve data for "ILULI" station under "DK" network code.

\section{AUTHOR CONTRIBUTIONS}

PV and MS were involved in planning and supervised the work. ZJ, GN, AH, PJ, PF, and FD contributed to the installation and performance of the sensors. PV, TD-J, and TL processed and interpret the Greenland data. ZJ performed the Longyearbyen data processes, noise analysis, drafted the manuscript and designed the figures. MS and ZJ discussed the Longyearbyen challenges. ZJ, PV, MS, and FD are mainly contributed to the manuscript editing.

\section{FUNDING}

This work was supported by Integrated Arctic Observation System (INTAROS) project which is funded by the European Union's Horizon 2020 Research and Innovation Program under GA No. 727890. 


\section{ACKNOWLEDGMENTS}

We acknowledge the Svalbard museum (Mikael Amadeus Bjerkestrand) and Radisson Blu Polar hotel (Kristoffer Halvarp) for hosting the geophones in Longyearbyen. The Piniakkanik Sumiiffinni Nalunaarsuineq (PISUNA) programme and Qeqertalik Municipality for advice and support in Greenland.

\section{REFERENCES}

Allen, R. M., Kong, Q., and Martin-Short, R. (2020). The myshake platform: a global vision for earthquake early warning. Pure Appl. Geophys. 177, 1699-1712. doi: 10.1007/s00024-019-02337-2337

Amante, C., and Eakins, B. W. (2009). ETOPO1 1 Arc-Minute Global Relief Model: Procedures, Data Sources and Analysis. NOAA Technical Memorandum NESDIS NGDC-24. Boulder, CO: National Geophysical Data Center, doi: 10. 7289/V5C8276M

Anthony, R. E., Ringler, A. T., Wilson, D. C., and Wolin, E. (2018). Do low-cost seismographs perform well enough for your network? An overview of laboratory tests and field observations of the OSOP Raspberry Shake 4D. Seismol. Res. Lett. 90, 219-228. doi: 10.1785/022018 0251

Clinton, J., Larsen, T., Dahl-Jensen, T., Voss, P., and Nettles, M. (2017). Special Event: Nuugaatsiaq Greenland Landslide and Tsunami. Incorporated Research Institutions for Seismology Washington DC. Available online at: https://ds.iris.edu/ds/nodes/dmc/specialevents/2017/ 06/22/nuugaatsiaq-greenland-landslide-and-tsunami/ (accessed March 20, 2020).

Clinton, J. F., Nettles, M., Walter, F., Anderson, K., Dahl-Jensen, T., Giardini, D., et al. (2014). Real-time geophysical data enhance Earth system monitoring in Greenland, Eos Trans. AGU 95, 13-14. doi: 10.1002/2014EO02 0001

Cochran, E. S., Lawrence, J. F., Christensen, C., and Jakka, R. S. (2009). The quakecatcher network: citizen science expanding seismic horizons. Seismol. Res. Lett. 80, 26-30. doi: 10.1785/gssrl.80.1.26

Cuyler, C., Daniel, C. J., Enghoff, M., Levermann, N., Møller-Lund, N., Hansen, P. N., et al. (2020). Using local ecological knowledge as evidence to guide management: a community led harvest calculator for muskoxen in Greenland. Conserv. Sci. Pract. 2:e159.

Dahl-Jensen, T., Larsen, L. M., Pedersen, S. A. S., Pedersen, J., Jespsen, H. F., Pedersen, G., et al. (2004). Landslide and Tsunami 21 November 2000 in Paatuut, West Greenland. Nat. Hazards 31, 277-287.

Danielsen, F., Johnson, N., Lee, O., Fidel, M., Iversen, L., Poulsen, M. K., et al. (2020). Community-based Monitoring in the Arctic. Fairbanks, AK: University Alaska Press.

Danielsen, F., Burgess, N. D., Balmford, A., Donald, P. F., Funder, M., Jones, J. P. G., et al. (2009). Local participation in natural resource monitoring: a characterization of approaches. Conserv. Biol. 23, 31-42. doi: 10.1111/j.15231739.2008.01063.x18798859

Danielsen, F., Enghoff, M., Magnussen, E., Mustonen, T., Degteva, A., Hansen, K. K., et al. (2017). Citizen Science Tools for Engaging Local Stakeholders and Promoting Local and Traditional Knowledge in Landscape Stewardship. The Science and Practice of Landscape Stewardship. Cambridge: Cambridge University Press, 80-89.

Danielsen, F., Topp-Jørgensen, E., Levermann, N., Løvstrøm, P., Schiøtz, M., Enghoff, M., et al. (2014). Counting what counts: using local knowledge to improve Arctic resource management. Polar Geogr. 37, 69-91. doi: 10.1080/ 1088937X.2014.890960

Darbyshire, F. A., Dahl-Jensen, T., Larsen, T. B., Voss, P. H., and Joyal, G. (2017). Crust and uppermost-mantle structure of Greenland and the Northwest Atlantic from Rayleigh wave group velocity tomography. Geophys. J. Int. 212, 1546-1569. doi: 10.1093/gji/ggx479
We are grateful to Lisbeth Iversen, Angel Rodriguez, Hanne Sagen, Stein Sandven and Terje Utheim for valuable support. We appreciate Nicolai Rinds for assistance in signal processing. We also thank the Arctic Ice sheet monitoring program (GLISN) and International Federation of Digital Seismograph Networks (FDSN). We appreciate the constructive comments of RA and MK. We also thank the associate editor, KC.

Gregersen, S. (1982). Earthquakes in Greenland. Bull. Geol. Soc. Denmark 31, 11-27. doi: 10.1007/978-94-009-2311-9_20

Havskov, J., Voss, P. H., and Ottemöller, L. (2020). Seismological observatory software: 30 Yr of SEISAN. Seismol. Res. Lett. doi: 10.1785/0220190313 [Epub ahead of print].

Hecker, S., Haklay, M., Bowser, A., Makuch, Z., and Vogel, J. (eds) (2018). Citizen Science: Innovation in Open Science, Society and Policy. London: UCL Press.

Hestnes, E., Bakkehøi, S., and Jaedike, C. (2016). "Longyearbyen, Svalbard vulnerability and risk management of an Arctic settlement under changing climate - a challenge to authorities and experts," in Proceedings Of the International Snow Science Workshop 2016, Breckenridge.

Hicks, S. P., Verdon, J., Baptie, B., Luckett, R., Mildon, Z. K., and Gernon, T. (2019). A shallow earthquake swarm close to hydrocarbon activities: discriminating between natural and induced causes for the 2018-2019 Surrey, United Kingdom, Earthquake Sequence. Seismol. Res. Lett. 90, 2095-2110. doi: $10.1785 / 0220190125$

Johnson, N., Alessa, L., Behe, C., Danielsen, F., Gearheard, S., GofmanWallingford, V., et al. (2015). The contributions of community-based monitoring and traditional knowledge to Arctic observing networks: reflections on the state of the field. Arctic 68(Suppl. 1), 28-40.

Manconi, A., Coviello, V., Galletti, M., and Seifert, R. (2018). Short communication: monitoring rock falls with the Raspberry Shake. Earth Surf. Dyn. 6, 1219-1227. doi: 10.5194/esurf-6-1219-2018

McNamara, D. E., and Buland, R. P. (2004). Ambient noise levels in the continental united states. Bull. Seismol. Soc. Am. 94, 1517-1527.

Misund, O. A. (2017). Academia in Svalbard: an increasingly important role for research and education as tools for Norwegian policy. Polar Res. 36:1308131. doi: 10.1080/17518369.2017.1308131

Nettles, M., and Ekström, G. (2010). Glacial earthquakes in Greenland and Antarctica. Annu. Rev. Earth Planet. Sci. 38, 467-491. doi: 10.1146/annurevearth-040809-152414

Penrose, D., and Call, S. M. (1995). Volunteer monitoring of benthic macroinvertebrates: regulatory biologists' perspectives. J. No. Am. Benthol. Soc. 14, 203-209.

Peterson, J. (1993). Observation and Modeling of Seismic Background Noise. Albuquerque, NM: U. S. Geological Survey.

Podolskiy, E. A., and Walter, F. (2016). Cryoseismology. Rev. Geophys. 54, 708-758. doi: 10.1002/2016RG000526

Raspberry Shake, S. A. (2016). Raspberry Shake - OSOP. International Federation of Digital Seismograph Networks. Dataset/Seismic Network. doi: 10.7914/SN/ AM

Root, T. L., and Alpert, P. (1994). Volunteers and the NBS. Science 263, 1205-1205.

Conflict of Interest: The authors declare that the research was conducted in the absence of any commercial or financial relationships that could be construed as a potential conflict of interest.

Copyright (c) 2020 Jeddi, Voss, Sørensen, Danielsen, Dahl-Jensen, Larsen, Nielsen, Hansen, Jakobsen and Frederiksen. This is an open-access article distributed under the terms of the Creative Commons Attribution License (CC BY). The use, distribution or reproduction in other forums is permitted, provided the original author(s) and the copyright owner(s) are credited and that the original publication in this journal is cited, in accordance with accepted academic practice. No use, distribution or reproduction is permitted which does not comply with these terms. 